ISSN 1518-3483

Licenciado sob uma Licença Creative Commons

\title{
Intelectuais sergipanos e o pensamento escolanovista
}

\section{Sergipe Intellectuals and the newschoolist thoughts Intelectuales de Sergipe y el pensamiento de la Nueva Escuela}

\author{
Anne Emilie Souza de Almeida Cabral[ ${ }^{[a]}$, Solyane Silveira Lima ${ }^{[b]}$ \\ [a] Universidade Tiradentes (UNIT), Aracaju, Sergipe, Brasil \\ [b] Universidade Federal do Recôncavo da Bahia (UFRB), Cachoeira, Bahia, Brasil
}

\section{Resumo}

Este artigo se propõe a analisar o pensamento de alguns intelectuais sergipanos a respeito da Educação e compreender como se efetivou o processo de transformação das ideias da Pedagogia Moderna para o ideário da Escola Nova. Portanto, neste estudo problematizaremos a atuação dos professores, Helvécio de Andrade (1864-1940), Rocha Lima (1897-1969) e Nunes Mendonça (1923-1983) por meio de documentos e obras que tratam dos referidos personagens e que expressam o pensamento educacional dos mesmos.

* AESAC: Mestra, e-mail: anne_cabral@hotmail.com.br

SSL: Doutora, e-mail: solylima@hotmail.com 
Primeiramente, abordamos a respeito da difusão da Escola Nova no contexto educacional brasileiro, quando integrantes da República buscavam meios para moralizar a educação brasileira. Em seguida, analisamos o pensamento dos intelectuais sergipanos que, conforme percebemos, pautavam as suas ideias na proposta escolanovista. E, por fim, apreendemos que o pensamento educacional sergipano, através de seus intelectuais, apropriou-se da tendência nacional da época.

Palavras-chave: Intelectuais sergipanos. Escola Nova. Pensamento educacional.

\section{Abstract}

This article aims to analyze the thoughts of some intellectuals from Sergipe about Education and understand how to make the process of transformation of the ideas of Modern Pedagogy for the ideals of the New School. Therefore, in this study we will also analyze the activities of teachers, Helvécio de Andrade (1864-1940), Rocha Lima (18971969) and Nunes Mendonca (1923-1983) through documents and works that deal with those characters and that express their educational thoughts. First, we are dealing with the respect for the dissemination of the New School in the Brazilian educational context, when members of the Republic were looking for ways to bring morality into the Brazilian education. Then, we analyzed the thoughts of intellectuals from Sergipe that, as we have seen, were more based their ideas on New School proposal. And, finally, we will learn that the educational thought in Sergipe will appropriate, through its intellectuals, the national tendency of that time.

Keywords: Sergipe Intellectuals. New school. Educational thought. 


\section{Introdução}

A partir da década de 20 do século passado, novas concepções educacionais permearam no contexto pedagógico brasileiro. Essas concepções estavam fundamentadas nos princípios da Pedagogia da Escola Nova e vieram atender a algumas ideias defendidas por membros da República.

Integrantes da República buscavam demonstrar uma educação com princípios pedagógicos ditos modernos no intuito de moralizar o país. Neste período o índice do analfabetismo era muito alto e muitos acreditavam que a culpa estava atrelada ao despreparo daqueles que estavam governando a Nação.

Diante desse quadro, houve pensadores que defendiam a criação de uma escola única, a qual formaria uma elite governante junto com uma população alfabetizada. "Na implantação política dessa escola, as proposições da pedagogia da Escola Nova são consideradas mais eficientes [...] sob o impacto da extraordinária difusão internacional da chamada pedagogia da educação nova" (CARVALHO, 1998, p. 241).

A difusão das ideias da Escola Nova no Brasil aconteceu quando intelectuais brasileiros, como Anísio Teixeira e Lourenço Filho, foram estudar nos Estados Unidos e, neste lugar, se apropriaram dos modernos preceitos pedagógicos fundamentados nas concepções pragmatistas. O método preconizado pelos estudiosos da educação, dentre eles John Dewey, era o método intuitivo ativo.

Segundo Valdemarim (2004), o referido método surgiu quando Dewey definiu a noção da experiência reflexiva. O aluno aprendia os conhecimentos depois de ter experienciado e refletido sobre o que ele vivenciou. $\mathrm{Na}$ realidade, essa experiência era a não acadêmica, a qual tinha o objetivo de despertar o interesse dos alunos.

No intuito de transformar a educação segundo os preceitos da Escola Nova, diversos intelectuais brasileiros se organizaram e criaram a Associação Brasileira de Educação (ABE). De acordo com Clarice Nunes (2000), a Associação foi criada no dia 16 de outubro de 1924, ela "era um órgão de iniciativa privada, cujo departamento carioca teria a função 
de coordenar vários departamentos a serem criados em níveis estaduais" (NUNES, 2000, p. 41).

Essa Associação buscava articular com os diferentes estados brasileiros para assim, poder divulgar e difundir os seus pilares: "saúde, moral e trabalho". O objetivo era para que cada estado criasse a sua associação e, como forma de incentivo, a Associação Nacional enviava circulares para os departamentos de Instrução Pública. Nessas circulares haviam pedidos aos governantes para que enviassem as legislações estaduais, algumas informações sobre educação e sobre os professores, com a finalidade de se criar cadastros na Associação Nacional (CARVALHO, 1998).

Isso foi o que aconteceu com Sergipe, quando no ano de 1925, um ano após a criação da Associação, o presidente deste órgão, Candido de Melo Leitão, solicitou ao Governador de Sergipe, Graccho Cardoso, que enviasse a legislação do ensino do Estado para que pudesse organizar um arquivo de legislação educacional brasileira, como se pode perceber através da circular que foi enviada ${ }^{1}$ :

Associação Brasileira de Educação

Pavilhão Argentino - Avenida das Nações

Rio, 1 de junho de 1925.

Exm $^{\circ}$ Snr. Dr. Graccho Cardoso,

M. D. Presidente do Estado de Sergipe,

Aracajú.

A Associação Brasileira de Educação - cujo Departamento do Rio de Janeiro foi fundado em Outubro do ano passado e de cujos objetivos constam a organização permanente da estatística da instrução no Brasil e a de um archivo de legislação nacional e estrangeira sobre ensino e questões correlatas_desejosa de iniciar, desde já, as referidas organizações, resolveu dirigir-se a V. Ex., solicitando com todo o empenho a sua valiosa cooperação, no sentido de facilitar-lhe, no que se refere ao Estado confiado á esclarecida direcção de V. Ex., os meios de realizar aquelles objectivos.

1 SERGIPE. Circular do presidente da Associação Brasileira da Educação para o Presidente do Estado Graccho Cardoso. APES ${ }^{1}$ G1961. 
É assim que, na qualidade de presidente da aludida Associação, peço a V. Ex. nos faça remeter a legislação sobre ensino no seu Estado, os programmas que ahí foram adoptados e estão em vigor, uma lista dos estabelecimentos officiaes de ensino dos diversos grãos e, si possível, também, dos particulares e finalmente, uma relação nominal dos professores officiaes de ensino normal, secundário e superior.

Antecipando os meus melhores agradecimentos pelo concurso que o patriotismo de V.Ex. vas proporcionar à obra em nos empenhámos, approveito a oportunidade para apresentar a V. Ex. os seus protestos de subida consideração e distincto apreço.

Cândido de Mello Leitão (SERGIPE, Circular expedido pelo Presidente da Associação Brasileira de Educação, 1925).

Essa articulação da Associação Brasileira de Educação com o Estado de Sergipe mobilizou intelectuais sergipanos para busca do conhecimento relacionado aos princípios escolanovistas. Diante do exposto, este artigo se propõe a analisar o que alguns intelectuais sergipanos pensavam a respeito da educação e compreender como se efetivou o processo de transformação do pensamento focado nas ideias da Pedagogia Moderna para o ideário da Escola Nova. Para o nosso estudo, analisamos a atuação dos professores Helvécio de Andrade (1864-1940), Rocha Lima (1897-1969) e Nunes Mendonça (1923-1983).

\section{Intelectuais sergipanos e o pensamento escolanovista}

\section{Helvécio de Andrade}

O professor Helvécio de Andrade 2 foi um dos intelectuais que contribuíram para a difusão das ideias da Pedagogia Moderna e do ideário

2 Helvécio de Andrade (1864-1940) foi professor da Escola Normal e Diretor da Instrução Pública no período de 1914 a 1918 e nos anos de 1931 a 1935 divulgou algumas obras defendendo o uso do método intuitivo no processo de ensino. Este intelectual se formou em Medicina na Bahia no ano 
escolanovista. Ele publicou obras nas áreas da medicina e da educação. Para a formação das alunas-mestres da Escola Normal, Helvécio publicou o livro "Curso de Pedagogia: Psicologia, Pedologia, e Higiene Escolar", em 1913 com o intuito de demonstrar, de maneira sistemática, os conhecimentos da Pedagogia Moderna destacando os aspectos higienistas.

Enquanto Aracaju passava por um processo de embelezamento, com projetos voltados para a modernização do espaço urbanístico, principalmente a partir do 'tabuleiro de Pirro', as instituições escolares acompanham essas mudanças estruturais por meio do remodelamento da arquitetura escolar. Concebidas pelos princípios das práticas higienistas, o objetivo era civilizar cultivando novos hábitos e, assim, regenerar a sociedade (VALENÇA, 2006, p. 108).

Helvécio de Andrade defendia o uso do método intuitivo como uma maneira de despertar o interesse do aluno. Ele era contra os castigos físicos, pois para ele "esse método produziria apenas meninos neurastênicos que estudavam mais pelo 'temor da férula' que por amor ao saber, ou mesmo, crianças negligentes que se habituavam aos castigos físicos e relaxavam" (VALENÇA, 2006, p. 138).

Uma das reformas que foram empreendidas por ele na Instrução Pública foi a inclusão da disciplina Moral e Cívica no programa dos grupos escolares, no ano de 1915. "A disciplina Educação Moral e Cívica tinha, para Helvécio de Andrade, o propósito de civilizar, tornar as crianças seres sociáveis e conscientes dos deveres patrióticos" (VALENÇA, 2006, p. 17).

de 1886. Trabalhou na área de medicina em Santos, no Estado de São Paulo, sendo que, decorrente os seus conhecimentos políticos, foi indicado como Inspetor Escolar desta cidade. Durante o período em que foi inspetor teve contato com as reformas realizadas na administração de Caetano de Campos. As reformas consistiam na inauguração de escolas em edifícios majestosos como os grupos escolares, a Escola Normal e o Grupo Escolar Modelo, anexo a esta última instituição. As reformas feitas estavam fundamentadas nos princípios da Pedagogia Moderna. Para saber mais ver VALENÇA, Cristina. Civilizar, regenerar e higienizar: a difusão dos ideais da Pedagogia moderna por Helvécio de Andrade 1911-1935. Dissertação (Mestrado em Educação) - Universidade Federal de Sergipe, 2006. 
Após Helvécio se tornar membro da Associação Brasileira de Educação (ABE), entrou em contato com outros intelectuais da educação, dentre eles os renovadores, e um dos pontos defendidos foi o uso do método intuitivo ativo. Através dos trabalhos publicados por Helvécio na área de Educação, Cristina Valença (2006) assevera que ele:

Defendia uma escola pública mais "educativa" que "instrutiva”. Além disso, discutiu, nesse texto, as dificuldades dos professores primários, a importância da aplicação dos processos de ensino da Escola Ativa e dos métodos de ensino para modernizar a instrução pública. Foi através desses textos e dos relatórios emitidos ao governo interventorial, em 1931 e 1932, que Helvécio de Andrade manifestou sua apropriação das concepções educacionais embasadas nos princípios defendidos pela Associação Brasileira da Educação (VALENÇA, 2006, p. 219).

Em Sergipe, o mesmo criou a Associação Sergipana de Educação (ASE), com o intuito de abordar temas relacionados à educação do Estado. Algumas das suas ideias coadunavam-se com as concepções abeanas, como o caso dos princípios da $\mathrm{ABE}$ que eram higienizar, racionalizar e nacionalizar. A ASE foi criada no dia 06 de fevereiro de 1934; a mesma era filiada à Associação Brasileira de Educação. Durante a fundação da ASE, estavam presentes professores da Escola Normal, diretores dos grupos escolares e inspetores ${ }^{3}$.

3 No dia da fundação, estavam presentes José Augusto da Rocha Lima, Francisco da Graça Leite, José Magalhães Carneiro, Joaquim Sobral, Florentino Teles de Menezes, Luiza Paes, Passos Cabral, José V. Teles de Menezes, funcionários da Instrução; Graciene Fernandes Barbosa, Andréa Quaranta, Maria Ávila Lima, Maria Amélia Fontes Santos, Laura Silva Baião, Dalva Bomfim Campos, Aloísia dos Santos Lima, Maria Regina de Oliveira, Nilda Ferreira Santos, Rosalva Brito, Maria da Glória Barros, Fausta de Mendonça Viana, Odelina de Almeida Quaranta, Josefina Nogueira, Maria José Oliveira, Perpedigna Cavalcante Menezes, Zélia Araújo Vieira e Silva, Odinéia Brito Mangueira, Maria Pureza Santana, Eliza Rocha, Maria Lima Santos Joana Maria da Silva Maria Oliveira Alves, Aurora Santos, Alocina Alves Leite, Eulina Lídio Araújo, Dulcinéia da Conceição Silva, Izabel de Santana, Inês Oliveira Freire, Isaura Carvalho Oliveira, Maria da Conceição Mendonça, professoras primárias (SERGIPE. Ata da fundação da Associação Sergipana de Educação. Diário Oficial de Sergipe, 1 de Abril de 1934, ano XVI, no 5927, p. 04). 
Logo assumiu a presidência da Instrução Pública e da Associação. De acordo com a ata de fundação, ele designou o Conselho Diretor da Associação Sergipana de Educação. Assim, o Conselho ficou composto pelos seguintes integrantes: Helvécio de Andrade, como presidente; José Augusto da Rocha Lima, como vice-presidente; um secretário; um tesoureiro; três membros do magistério primário e três membros do magistério primário da capital.

Após a concretização da fundação da ASE, o seu estatuto foi elaborado. O mesmo determinava que a Associação devia ser mantida através da contribuição mensal dos sócios filiados a ela. Com o estatuto, uma comissão de professores designada por Helvécio de Andrade4 foi ao Palácio do Governo para comunicar ao Interventor sobre a fundação da ASE. No dia 29 de junho de 1934, foi registrado no Jornal Diário Oficial o parecer de aceitação da filiação da ASE à Associação Brasileira de Educação:

Associação Sergipana de Educação

Para conhecimento do professorado sergipano e dos sócios da ASE, damos abaixo o seguinte:

Parecer

Tendo presentes o Estatuto da Associação Sergipana de Educação, fundada em fevereiro findo no Estado de Sergipe, e havendo recebido ofício em que o presidente da mesma Associação, Dr. Helvécio Andrade, solicita a sua filiação a $\mathrm{ABE}$, declaro que verifiquei estarem no caso preenchidas as condições exigidas pelo artigo 13 dos Estatutos desta e, assim, opino, em face do art. $6^{\circ}$ do Regimento Interno, que seja concedida sem demora a filiação solicitada. Rio, 31 de maio de 1934 - M. B. Lourenço Filho, presidente da Associação Brasileira de Educação. (SERGIPE, Diário Oficial da União, 1934)5.

4 Esta comissão foi composta pelos professores Passos Cabral, José Augusto da Rocha Lima e Graças Leite. SERGIPE. Jornal Diário Oficial do Estado de Sergipe. 29 de junho de 1934, ano XVI, no 5920, p. 03. APES I'56

5 SERGIPE. Jornal Diário Oficial. 29 de junho de 1934, ano XVI, no 5989, p. 03. APES I156 
Apesar de Helvécio ser adepto de alguns ideais dos renovadores, ele não concordava com um dos princípios defendidos por eles: o ensino laico. O intelectual defendia a necessidade de se ensinar a moral católica nas escolas, utilizando o método intuitivo na transmissão desses conhecimentos.

\section{José Augusto da Rocha Lima}

Outro estudioso responsável por difundir juntamente com Helvécio de Andrade as ideias escolanovistas, foi o professor José Augusto da Rocha Lima, que trabalhou na Instrução Pública de Sergipe durante onze anos (1931 - 1942). Este teve um papel fundamental no processo de difusão das ideias paulistas em Sergipe, devido aos estudos realizados no sul do país sobre as novas práticas pedagógicas.

É emblemática a figura deste intelectual que, apesar de não ter sido estruturado ou destacado como um dos difusores de métodos e técnicas pedagógicas pautadas na Escola Nova, se empenhou na tarefa de realizar estudos teóricos e práticas a respeito para serem adotados na instrução pública, dando-nos indicativos de sua importância no contexto da reforma educacional em Sergipe, na década de 1930, ao mediar a construção de uma cultura escolar representava os anseios das classes dirigentes então decididas a construir o "Estado Novo" (SOBRAL, 2002, p. 09).

No ano de 1931, Rocha Lima foi indicado para realizar uma viagem a São Paulo, no intuito de estudar os novos métodos e as técnicas de ensino para serem adotados em Sergipe. Na viagem, visitou estabelecimentos de ensino e teve contato com as atividades pedagógicas desenvolvidas nesses estabelecimentos.

Durante os dias em que ficou em São Paulo, ele descreveu as visitas que fez e os contatos que teve, elaborando assim, um relatório. Em 
relação ao documento, Neide Sobral (2002) demonstra a opinião de Rocha Lima no tocante à aplicação das ideias da Escola Ativa.

No referido relatório, José Augusto da Rocha pergunta: "Podemos realizar em Sergipe a Escola Ativa?” (Rocha Lima, 1931, p. 46). Reconhecendo que a escola é uma questão vital para o Brasil, um Brasil novo, uma escola nova, aponta as dificuldades pelas quais passa a escola sergipana e pede prudência para evitar-se o "salto no escuro". Propõe então "ensaiar a Escola Ativa na capital e nas principais cidades, nos grupos escolares e na Escola de Aplicação anexa à Escola Normal" (SOBRAL, 2002, p. 03).

Ainda em relação ao documento, José Augusto da Rocha Lima demonstrou contato com um dos pioneiros da educação, Lourenço Filho, o qual acompanhou aquele inspetor para conhecer a instrução pública da cidade de São Paulo. Para fundamentar o seu relatório, o inspetor Rocha Lima se apropriou das concepções de Ferriére ${ }^{6}$, Claparéde $^{7}$, Dewey, Decroly ${ }^{8}$, Montessori $^{9}$, integrantes do discurso pedagógico que elaboraram métodos de ensino presentes no ideário escolanovista. Rocha Lima não condenava por completo a Escola Tradicional, mas alertava que a Escola Nova veio modificar alguns aspectos da Pedagogia Antiga.

6 Para Ferriére (1879-1960) a escola devia se transformar profundamente, colocando no centro de suas atividades o jogo e o trabalho. A formação devia ter um caráter democrático reforçando os aspectos de autonomia e a vida escolar devia se fundamentar no sistema de autogoverno. (CAMBI, 1999)

7 Para Claparéde (1873-1940) a escola devia se organizar sob medida para as crianças, a aprendizagem tem que ser individual, respeitando o desenvolvimento de cada criança e oferecer vários tipos de atividade para que o aluno possa escolher. (CAMBI, 1999)

8 Ovídio Decroly (1871-1932) era médico e realizou trabalhos com "crianças" anormais. Ele desenvolveu uma nova forma de ensino denominada "centros de interesse" e aulas globalizadas. (CAMBI, 1999)

9 Montessori (1870- 1952) foi médica e se dedicou para cuidar de crianças excepcionais. Ela acrescentou a ideia de que a criança deve desenvolver livremente suas próprias atividades para amadurecer as suas capacidades, porém a liberdade defendida por Montessori não é a mesma coisa que esponteneísmo. (CAMBI, 1999) 
Apesar de Rocha Lima ter viajado com o intuito de verificar os aspectos educacionais daquele Estado, o mesmo afirmou em relatório que Sergipe não devia copiar os padrões de ensino da escola paulista, visto que havia diferenças entre São Paulo e Sergipe. O ideal era analisar as instruções vistas em São Paulo e adaptá-las à realidade de Sergipe.

Analisando a instrução pública de São Paulo, Rocha Lima fez algumas considerações para melhorar o ensino em Sergipe. Uma delas foi o alerta que deu para a necessidade de se atentar com o cuidado da Biblioteca Pedagógica, a qual se encontrava anexa à Diretoria da Instrução, com o objetivo de fornecer aos professores instrumentos teóricos sobre as ciências pedagógicas e suas aplicações na educação.

Além disso, ele ressaltou a intensa propaganda que era realizada em São Paulo para conquistar os professores em prol da utilização dos novos princípios pedagógicos. Os mecanismos para difundir as "novas" concepções pedagógicas davam-se por meio de palestras e conferências (SERGIPE, Relatório de Rocha Lima, 1931, p. 01).

No tocante ao ensino, Rocha Lima advertiu que a instrução fosse uma preparação, o ensino não podia estar desarticulado do cotidiano social, o mesmo servia para que o aluno tivesse conhecimento do meio em que vivia. Por isso, sustentava que a escola deve preparar para a vida "em vez de se limitar ao aprendizado de técnicas (leitura, escrita, ortografia, cálculo) e ao ensino verbal de geografia, história, e de outra ciência morta" (SERGIPE, Relatório de Rocha Lima, 1931, p. 12).

Todo o programa de ensino devia se desenvolver de acordo com os interesses do aluno para que, no processo de aprendizagem, fosse empreendida uma iniciativa por parte do educando. Diante disso, o método de ensino considerado por ele era o de aulas globalizadas, defendido por Ovídio Decroly: "Desde que se separa a atividade do interesse, adverte Dewey, cria-se uma luta entre dois polos da atividade. Formam-se hábitos mecânicos visíveis pelo movimento externo, mas onde se acha ausente a capacidade de reação" (SERGIPE, Relatório de Rocha Lima, 1931, p. 13). 


\section{Antônio Nunes Mendonça}

Outro intelectual escolanovista que teve uma atuação em Sergipe foi José Antônio Nunes Mendonça. Segundo Josefa Eliana de Souza (2003), Nunes Mendonça foi deputado estadual e professor do Instituto de Educação Rui Barbosa.

Josefa Eliana de Souza (2003) comenta que os princípios escolanovistas estavam presentes no Estado desde o final do século XIX, porém, essas ideias tiveram maior destaque a partir do momento que foram sistematizadas por Nunes Mendonça, em seu livro A Educação em Sergipe.

Tal como em A Cultura Brasileira, o trabalho desenvolvido pelo professor Nunes Mendonça em A Educação em Sergipe fazia parte de um projeto maior. Se para o primeiro representou uma encomenda da CNN, para o segundo foi uma tarefa atribuída pelo Centro Brasileiro de Pesquisas Educacionais (CBPE), órgão do Instituto Nacional de Estudos Pedagógicos (SOUZA, 2003, p. 121).

O escolanovista foi estagiário do Instituto Nacional de Estudos Pedagógicos (INEP)10, o qual tinha como diretor, naquela época, Anísio Teixeira. Nunes Mendonça conviveu com escolanovistas e foi incumbido de realizar uma pesquisa sobre a educação em Sergipe. O seu livro é um estudo sociológico escrito em 1956; porém, a publicação ocorreu apenas em 1958.

10 O INEP foi criado no dia 13 de janeiro de 1937, por meio do Decreto de no 580 . Inicialmente era denominado de Instituto Nacional de Pedagogia, depois passou a Instituto Nacional de Pesquisa e Estudos Educacionais. "Segundo o Decreto-Lei, cabia ao Inep 'organizar a documentação relativa à história e ao estado atual das doutrinas e técnicas pedagógicas; manter intercâmbio com instituições do País e do estrangeiro; promover inquéritos e pesquisas; prestar assistência técnica aos serviços estaduais, municipais e particulares de educação, ministrando-lhes, mediante consulta ou independentemente dela, esclarecimentos e soluções sobre problemas pedagógicos; divulgar os seus trabalhos'. Também cabia ao Inep participar da orientação e seleção profissional dos funcionários públicos da União" (BRASIL, 2008). BRASIL, História do Inep. 2008. Disponível em: <http://www.inep.gov.br/institucional/historia.htm> Acesso em: 08 abr. de 2008. 
O seu trabalho é um relatório de estudo apresentado ao Centro de Pesquisas Educacionais e foi com ele que Nunes Mendonça concorreu para o cargo de Professor Catedrático de Pedagogia do Instituto de Educação "Ruy Barbosa". Para a realização do estudo, o intelectual utilizou técnicas do método histórico e do normative survey.

Nunes Mendonça demonstrou no início do trabalho os aspectos socioculturais e econômicos, pois acreditava que os mesmos influenciavam na educação. Em seguida, o autor do livro "Educação Sergipana" abordou a situação educacional dos vários níveis de Educação em Sergipe: o ensino primário, supletivo, médio, agrícola e superior. Outros assuntos também foram comentados por Nunes Mendonça, tais como a relação da Política e Educação, a Constituição Estadual, as peculiaridades do professor primário e do ensino normal e a relação da família e escola.

Uma das conclusões obtidas em sua análise foi a de que as reformas na educação do Estado sergipano ficaram restritas no papel, ou seja, o uso dos preceitos escolanovistas não foi atingido na prática do ensino. As reformas em Sergipe, como em outras partes do Brasil, processavam-se no papel por meio de uma mera mudança de rótulo.

[...] quase sempre, para atender exigências da legislação federal. É o que vem acontecendo, por exemplo, com o ensino normal. A última reforma efetuada pela lei $n^{\circ} 30$ de 4 de dezembro de 1947, para admoesta-lo as exigências da Lei Orgânica Federal, na prática não reformou cousa alguma (MENDONÇA, 1958, p. 20).

Ele defendia a formação de uma sociedade democrática. Com este entendimento, concebeu a Escola Nova como um movimento favorável na formação desta sociedade. Não muito diferente dos pioneiros da educação que visualizavam a escola como um meio de transformar a sociedade, Nunes Mendonça acreditou que seria através dela que os problemas sociais seriam resolvidos. Para ele a educação devia ser gratuita, única e de responsabilidade do Estado. Este tipo de escola 
determinava que as pessoas fossem formadas de acordo com as suas capacidades (SOUZA, 2003).

A educação não podia estar voltada somente para a instrução; educar o indivíduo nos moldes intelectuais, físicos e mentais era a função da escola para que a pessoa agisse no meio social segundo os preceitos democráticos. Diante disso, Nunes Mendonça teceu críticas ao ensino elementar de Sergipe, visto que, na sua concepção, a escola não estava educando: "A escola elementar, em Sergipe, não educa, apenas fornece conhecimentos informativos e, mesmo aferidas segundo o padrão clássico, pelo estalão tradicional, são falhas" (MENDONÇA, 1958, p. 127).

Outro fator discutido pelo autor foi o número reduzido de estudantes matriculados nas instituições educacionais. Os motivos alegados pelo intelectual foram a pouca ampliação da rede escolar, além da má distribuição dos estabelecimentos de ensino no território sergipano. Verificou também que havia uma grande solicitação por parte da população para ter acesso à escola; por conseguinte, alegou que alguns estabelecimentos escolares localizavam-se em locais impróprios.

Na capital, onde as solicitações escolares são enormes, existem dois Grupos, que, instalados ambos no mesmo prédio e em local absolutamente impróprio, não apresentam rendimento razoável. Trata-se dos Grupos Escolares "Barão de Maruim" e "General Siqueira". Situados na mesma área residencial de pessoas abastadas, distantes das áreas onde habita a clientela das escolas públicas, a matrícula de cada um não chega a duzentos alunos, enquanto outros, localizados em sítios adequados, necessitam de recorrer ao tresdobramento para as matrículas elevadíssimas (MENDONÇA, 1958, p. 70).

Toda esta crítica estendeu-se às ações do Estado, uma vez que, de acordo com o mesmo, as escolhas da localização dos prédios não eram feitas para satisfazer a população, e sim às questões políticas. Na XII Conferência Nacional de Educação, Nunes Mendonça comentou, em seu livro, acerca da apresentação de um trabalho que fornecia sugestões para 
diminuir a intervenção político-partidária na administração da Educação (MENDONÇA, 1958).

A participação na Conferência demonstra que ele teve contato com diferentes intelectuais da educação, apropriando-se das ideias de alguns deles, como Anísio Teixeira e Lourenço Filho, para fundamentar as suas concepções relacionadas à educação: "Ontem, parafraseando o professor Anísio Teixeira, queríamos educar Sergipe e hoje é Sergipe que quer ser educado" (MENDONÇA, 1958, p. 105).

Nunes Mendonça (1958) defendia que o ensino devia estar fundamentado nos princípios da Pedagogia Ativa e, para isso, o programa devia ser realizado por meio de um conjunto de atividades e experiências dos alunos. Para o escolanovista, em Sergipe não havia espaços adequados e nem professores capacitados para o exercício de tal função. Sobre o programa, Nunes Mendonça afirmou que:

Não se compreendeu ainda a necessidade de organizar o currículo como conjunto de atividades e experiências da criança a serem utilizadas pela escola de acordo com os objetivos visados [...] A falta de docentes devidamente preparados e de material didático, aliás, seriam entraves poderosos e de material a ensaios e tentativas (MENDONÇA, 1958, p. 135).

Também era contra o ensino memorialista e, para a formação do educando, por meio das suas experiências, ele dizia que o fundamental era socializar o aluno. A socialização que Nunes Mendonça defendia era a não aceitação passiva dos meios sociais, mas uma aprendizagem sobre como refletir os fatos existentes na comunidade. Para isso, a escola tinha que se tornar uma "comunidade em miniatura", proposta esta trabalhada por Dewey (1978).

Para oferecer, portanto, condições de formação da personalidade, a escola precisaria tornar-se um pequeno meio social, uma "embryonic community life". "A aprendizagem, como revela Kilpatrick, exige sempre a experiência real em situação social” (MENDONÇA, 1958, p. 130). 
No tocante ao ensino primário, mais especificamente aos grupos escolares, este autor trouxe a seguinte afirmação: "Planejados para um programa intelectualista, para o tipo de 'escola ouvir' ou 'escola sentada', os grupos escolares do Estado, em sua maioria, não possuem condições de favorecer o ensino ativo" (MENDONÇA, 1958, p. 124).

A crítica à situação material das escolas, apresentada por Helvécio de Andrade na década de 30, era também feita vinte anos depois, por Nunes Mendonça, para quem o poder público não havia dado a merecida atenção às escolas dessa rede e por isso elas não estão preparadas para as exigências demográficas, tendo sido insignificante o número de grupos construídos (SOUZA, 2003, p. 147).

Como demonstra Souza (2003), desde o início do século houve essa discussão das condições de materiais para o desenvolvimento do ensino. Com a Pedagogia Moderna, a adoção de princípios higienistas e a adoção do método intuitivo necessitava que os locais de ensino fossem arejados e ventilados, além disso, o ensino que devia desenvolver os sentidos teria que ter diversos materiais (mapas, globos, cartas de Parker, dentre outros) para que a aprendizagem partisse do concreto.

A partir da década de 20 do século passado, com os princípios escolanovistas, intelectuais sergipanos, dentre eles Helvécio de Andrade, teve a oportunidade de conhecer os preceitos da Escola e passou a defender não somente a necessidade em atender aos princípios higienistas, mas também a adotar padrões de ensino em que, além da criança observar, era necessário experimentar, despertando o interesse dos alunos pela aprendizagem, outros intelectuais também se apropriaram do discurso da Escola Nova.

A relação que a Associação Brasileira da Educação buscou desenvolver com os diferentes estados brasileiros, permitiu que muitos intelectuais, dentre eles os sergipanos, que já defendiam os interesses da Pedagogia Moderna, acrescentassem a esta as ideias da Escola Nova. 


\section{Considerações finais}

No início do século passado quando intelectuais brasileiros se apropriaram das concepções pragmatistas, alguns deles, como Anísio Teixeira e Lourenço Filho, passaram a difundir essas ideias para o cenário educacional brasileiro, isso fez com que diferentes estudiosos na área da educação fizessem viagens para os estados de São Paulo e Rio de Janeiro no intuito de entender os princípios da Pedagogia da Escola Nova.

A partir dessa sistemática, estudiosos, como Rocha Lima, realizaram viagens com objetivo de verificar como eram desenvolvidas a instrução nos importantes centros brasileiros (São Paulo, Rio de Janeiro) e adaptá-las à realidade sergipana. Quando os princípios escolanovistas já estavam sendo consolidados no cenário educacional sergipano, na perspectiva do pensamento educacional, Nunes Mendonça tece críticas a respeito da educação em Sergipe devido a mesma não estar adequada ao que determina o ideário da Escola Nova. Fato que demonstra que as transformações não ocorreram de maneira abrupta, mas foi um processo que ocorreu paulatinamente, durante anos.

As ideias da Escola Nova foram acrescentadas aos princípios da Pedagogia Moderna, visto que a diferença entre elas é tênue. A Pedagogia Moderna adota o método intuito, já o escolanovismo defendia o método intuitivo ativo, no qual a criança era desafiada a experimentar. A Pedagogia Moderna defendia o uso de materiais concretos, a Escola Nova, além de se usar os materiais concretos, os alunos tinham que buscar outros artefatos para se compreender os conteúdos. Na Pedagogia Moderna os espaços precisavam ser arejados e ventilados para atender aos princípios higienistas, com o ideário da Escola Nova esses princípios permaneceram.

Portanto, observamos que as mudanças que aconteceram no campo educacional sergipano no período estudado, decorreram da difusão das ideias da Escola Nova apropriadas pelos intelectuais locais. Estes, por sua vez, não mediram esforços para disseminá-las por meio de programas, associações, da imprensa e pelos livros que publicaram e que se destinava a formação dos futuros professores primários. 
Dessa maneira, torna-se evidente que Helvécio de Andrade, Rocha Lima e Nunes Mendonça não apenas aderiram ao pensamento educacional escolanovista posto nacionalmente, mas comungaram e o divulgaram no cenário educacional sergipano.

\section{Referências:}

BRASIL, História do Inep. Disponível em: <http://www.inep.gov.br/institucional/ historia.htm> Acesso em: 08 abr. de 2008.

CAMBI, Franco. História da Pedagogia. São Paulo: UNESP, 1999.

DE CARVALHO, M. M. C.. Molde Nacional e forma cívica: higiene, moral e trabalho no projeto da Associação Brasileira de Educação (1924 - 1931). Bragança Paulista: EDUSF, 1998.

. Reforma da Instrução Pública. In: Lopes, Eliane (et al..)

(Org.). 500 anos de Educação no Brasil. $3^{\mathrm{a}}$ ed. 1 reimp., Belo Horizonte: Autêntica, 2007. p. 225-252.

CARVALHO, R. A.; VIEIRA, L. C. A Caixa Escolar e a Bandeira Republicana. In: Anais ... O ensino e a Pesquisa em História da Educação, 09 a 12 de novembro de 2008. Universidade Federal de Sergipe; Universidade Tiradentes, 2008. CD-ROM DEWEY, J. Vida e Educação. Tradução Anisio Teixeira. 10 ed. São Paulo: Melhoramentos, 1978.

MENDONÇA, J. A. N. A Educação em Sergipe. Aracaju: Livraria Regina, 1958.

NUNES, C. Anísio Teixeira: a poesia da ação. Bragança Paulista,: EDUSF, 2000.

SERGIPE. Ata da fundação da Associação Sergipana de Educação. Diário Oficial de Sergipe, 1 de Abril de 1934, ano XVI, nº 5927, p. 04.

SERGIPE. Circular do presidente da Associação Brasileira da Educação para o Presidente do Estado Graccho Cardoso, 1925. APES G11961. 
SERGIPE. Jornal Diário Oficial. 29 de junho de 1934, ano XVI, nº 5989, p. 03. APES I ${ }^{1} 56$

SERGIPE. Jornal Diário Oficial do Estado de Sergipe, 1 de Abril de 1934, ano XVI, no 5927, p. 05. APES I ${ }^{1} 56$.

SERGIPE. Jornal Diário Oficial do Estado de Sergipe, 21 de junho de 1934, ano XVI, $\mathrm{n}^{\circ} 5920$, p. 03. APES I ${ }^{1} 56$.

SERGIPE. Relatório de Rocha Lima apresentado ao Sr. Interventor Federal, 23 de junho 1931. APES. Acervo de Sebrão Sobrinho, caixa nº 10.

SOBRAL, N. Ecos de uma viagem: Rocha Lima e a Escola Nova em Sergipe. In: Anais...: História e memória da educação brasileira. Universidade Federal do Rio Grande do Norte. Natal: Editora Núcleo de Arte e Cultura, 2002. CD-ROM

SOUZA, J. E. Nunes Mendonça: um escolanovista sergipano. São Cristóvão: Editora UFS; Aracaju: Fundação Oviêdo Teixeira. 2003.

VALDEMARIM, V. T. Os sentidos e a experiência: professores, alunos e métodos. In: SAVIANI, D.; ALMEIDA, J. S.; SOUZA, R. F.; VALDEMARIM, V. T. O legado educacional do século XX no Brasil. Campinas: Autores Associados, 2004. p. 164 $-203$.

VALENÇA, C. Civilizar, regenerar e higienizar: a difusão dos ideais da Pedagogia moderna por Helvécio de Andrade 1911-1935. 2006. Dissertação (Mestrado em Educação) — Universidade Federal de Sergipe, 2006.

Recebido: 15/06/2015

Received: 06/15/2015

Aprovado: 25/10/2015

Approved : 10/25/2015 
